\title{
Silvio Serangeli, Stendhal Civita-Vecchia
}

\author{
Michel Arrous
}

\section{(2) OpenEdition}

\section{Journals}

\section{Édition électronique}

URL : http://journals.openedition.org/studifrancesi/5669

DOI : 10.4000/studifrancesi.5669

ISSN : 2427-5856

\section{Éditeur}

Rosenberg \& Sellier

\section{Édition imprimée}

Date de publication : 1 septembre 2011

Pagination : 425

ISSN : 0039-2944

\section{Référence électronique}

Michel Arrous, «Silvio Serangeli, Stendhal Civita-Vecchia », Studi Francesi [En ligne], 164 (LV | II) | 2011,

mis en ligne le 30 novembre 2015, consulté le 13 janvier 2021. URL : http://journals.openedition.org/ studifrancesi/5669; DOI : https://doi.org/10.4000/studifrancesi.5669

\section{Ce document a été généré automatiquement le 13 janvier 2021.}

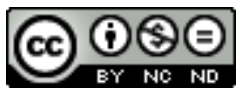

Studi Francesi è distribuita con Licenza Creative Commons Attribuzione - Non commerciale - Non opere derivate 4.0 Internazionale. 


\title{
Silvio Serangeli, Stendhal Civita- Vecchia
}

\author{
Michel Arrous
}

\section{RÉFÉRENCE}

SILVIO SERANGELI, Stendhal Civita-Vecchia, Giornate stendhaliane internazionali di Civitavecchia, Associazione "Angelo Mori”, Civitavecchia, Fondazione Cassa di Risparmio di Civitavecchia, 2010, 427 pp. - Stendhal Civita-Vecchia, DVD, Associazione Culturale “Angelo Mori”, Fondazione Cassa di Risparmio di Civitavecchia, 2010.

1 Ce «trou abominable» dans lequel L'Ennuyé ou le Baron Dormant a connu la plus triste période de sa vie a fait l'objet, avec le concours de diverses institutions, d'une sympathique opération de promotion touristique intitulée «Journées internationales de Civitavecchia» (6-11 décembre 2010), brillante commémoration des célébrations de 1924 et 1964, avec inauguration de la plaque restaurée du largo Plebiscito en l'honneur de Stendhal. Abeille, Ape, Cityold, autrement dit Civitavecchia, qui n'est certes plus cette triste et laide petite ville où il s'ennuya tant, vient d'illustrer sa vitalité culturelle en célébrant non sans faste «son» grand homme: un fort volume de plus de trente chapitres et un DVD de 105 minutes sur le consul, sa vie et ses œuvres, sur la Civitavecchia du $\mathrm{XIX}^{\mathrm{e}}$ siècle, sur les livres de l'écrivain et leur destin dans la famille Bucci, les fonds des Bibliothèques de Grenoble, Milan (palais Sormani) et Rome (Fondation Primoli), où l'on retrouve une partie de la généreuse iconographie rassemblée par Silvio Serangeli. Quant au livre, consacré à la vie de Civitavecchia à l'époque de Stendhal et à ses activités de consul, il est bourré de statistiques et d'informations techniques qui constituent une analyse des réalités économiques et sociales à partir de la lecture de la correspondance consulaire ou privée de Stendhal. On découvre le trafic du port des États pontificaux dans ses principaux aspects: pêche et flotte marchande - on saura tout sur les bateaux à vapeur, leur expansion à partir de 1830 , leurs avaries ou leurs naufrages -, sur l'arsenal et ses forçats, sur les portefaix et les petits polissons qu'on voit dans Don Pardo, le lazaret, les voyageurs et les touristes 
qui veulent rencontrer la seconde gloire locale, le très fameux bandit Antonio Gasparone, épigone de Barbone, qui a l'air d'un bon papa de l'Apennin. Il est aussi question du spectre du choléra, du conflit qui opposa le consul à Luigi Romanelli, commissaire à la santé, et de la visite de Grégoire XVI (20-25 mai 1835) que Stendhal manqua à cause de la goutte. Sont aussi évoquées les festivités et cérémonies locales observées par Stendhal, ainsi que le petit monde du consulat: Toto, sauvé des galères grâce au faux témoignage du consul, le domestique Baldoni et, bien sûr, le Caftangioglou dans son rôle de délateur patenté spécialiste du double jeu. On sait ce que Stendhal a pensé de la bourgeoisie locale et des notables - S. Serangeli cite la dynastie des Guglielmi, qu'il connaît fort bien et que Stendhal mentionne dans un rapport à Guizot -; heureusement, il y avait l'érudit Manzi et surtout D. Bucci et les Étrusques pour échapper à l'unique café et au vieux théâtre. Ajoutons que Rome n'était qu'à quatorze lieues! En lisant ce très consciencieux travail à la gloire d'un «village de sept mille quatre cents habitants», il se peut que les stendhaliens, qui disposaient déjà des recherches de F. Boyer et F. Barbaranelli, n'y fassent pas de grandes découvertes; en revanche, aucun d'entre eux ne pensera que Stendhal eut bien tort de se prendre pour Ovide chez les Scythes! À Civitavecchia, il a dit qu'il touchait à la barbarie, qu'il sombrait même dans le marasme, mais son ennui fut fécond. À ce sujet, il est dommage que n'ait pas été publiée la communication d'Hélène de Jacquelot sur «L'atelier de Stendhal à Civitavecchia», ni celle de Gérald Rannaud intitulée "Choses vues, ou les tribulations d'un écrivain consul». 